\title{
O Folclore na mídia de massa: Globo rural e aspectos folclóricos do homem do campo
}

\author{
Elizabeth Moraes Gonçalves ${ }^{1}$ \\ Universidade Metodista de São Paulo \\ bethmgoncalves@terra.com.br
}

\begin{abstract}
Resumo: O presente artigo apresenta resultados de pesquisa realizada sobre a imagem do homem do campo, construída pelo programa televisivo Globo Rural, da Rede Globo de televisão. Trata-se de parte da pesquisa intitulada "O Rural na Televisão: Uma análise do discurso rural construído pelo programa televisivo Globo Rural", do projeto mais amplo denominado Linguagens e discursos Especializados na Comunicação. Verificou-se que a tradição brasileira - representada pelos universos do caipira e do sertanejo e a modernidade tecnológica e científica aplicada ao campo se mesclam na composição de um programa televisivo que atende ao mesmo tempo o público rural e o urbano, criando a representação simbólica desta "moderna" cultura do campo. Caracteriza-se como uma pesquisa qualitativa, em que a leitura dos dados levantados como corpus para a pesquisa, foi subsidiada por elementos da análise crítica do discurso. Refletimos sobre o papel da Rede Globo, como mídia massiva, de caráter comercial, cumprindo, de certa forma, a tarefa de revitalizar aspectos folclóricos, entendidos como traços arraigados, segundo a emissora, à cultura e à imagem do homem campo.
\end{abstract}

Résumé: Cet article présente des résultats effectués par la recherche du image de l'homme du champ, construit par le programme d'émission télévisée Globo Rural, de la télévision de Rede Globo. C'est environ une partie de la recherche intitled "agricole dans la télévision : Une analyse de l'agricole discours construit par le programme d'émission télévisée Globo rural ", une partie du plus large projet appelé Les langues et les discours se sont spécialisés dans la communication. On l'a vérifié que tradition brésilienne représentée par les univers de "caipira" et d'"sertanejo" - et le technologique et le modernisme scientifique s'est appliqué au champ sont mélangés dans la composition de a télévisant le programme qui se focalise en même temps au public agricole et urbain, créant la représentation symbolique de ce "moderne" culture du champ. Il est caractérisé comme recherche qualitative, où la lecture des données augmentées comme corpus pour la recherche, a été subventionnée près éléments de l'analyse critique du discours. Nous réfléchissons sur le papier de Rede Globo, comme des médias massifs, de caractère commercial, accomplissant, dans un certain la manière, le charger de revitaliser des aspects folcloric, compris comme racine trace, selon le radiodiffuseur, à la culture et à l'image de l'homme du champ.

Summary: This article presents results carried out through research of the image of the man of the field, constructed by the televising program Globo

\footnotetext{
${ }^{1}$ Doutora em Comunicação pela UMESP e Mestre em Língua Portuguesa pela PUC-SP. Professora do Programa de Pós-Graduação Stricto Sensu em Comunicação Social da Universidade Metodista de São Paulo - UMESP, responsável pelo Projeto "Linguagens e Discursos Especializados na Comunicação".
} 
Rural, of the Rede Globo television. It is about a part of the research intitled "Agricultural in the Television: An analysis of the agricultural speech constructed by the televising program Globo Rural", part of the broader project called Languages and speeches Specialized in the Communication. It was verified that Brazilian tradition - represented by the universes of "caipira" and of "sertanejo" - and the technological and scientific modernism applied to the field are mixed in the composition of a televising program that focuses at the same time to the agricultural public and the urban one, creating the symbolic representation of this "modern" culture of the field. It is characterized as a qualitative research, where the reading of the data raised as corpus for the research, was subsidized by elements of the critical analysis of the speech. We reflect on the paper of Rede Globo, as massive media, of commercial character, fulfilling, in a certain way, the task to revitalize folcloric aspects, understood as root traces, according to the broadcaster, to the culture and the image of man of the field

Resumen: El artículo presenta resultados obtenidos con la investigación de la imagen del hombre del campo, construido por el programa agrícola Globo Rural, de la Rede Globo televisión. Esto es sobre parte de la investigación llamada "Agrícola en la televisión: Un análisis del discurso agrícola construido por el programa Globo Rural", parte del proyecto más amplio llamado Idiomas y discursos especializados en la comunicación. Fue verificado esta tradición brasileña - representada por los universos de "caipira" y del "sertanejo" - y el modernismo tecnológico y científico aplicado al campo si mesclan en la composición de un programa televisivo que objectiva al mismo tiempo el público agrícola y el urbano, creando la representación simbólica de esta cultura "moderna" del campo. Se caracteriza como investigación cualitativo, para donde la lectura de los datos levantados como base de la investigación, fue subvencionada por los elementos del análisis crítico del discurso. Reflejamos en el papel de la Rede Globo, como midia massiva, de carácter comercial, satisfaciendo, de cierta forma, la tarea de revitalizar aspectos folclóricos, entendido como los traçosarraigados, según la emisora, a la cultura y la imagen del hombre del campo.

Palavras-chave: Comunicação, linguagem, discurso, Rural, Folkcomunicação.

Mots-clé: Communication, langue, discours, agricole, Folkcommunication.

Keywords: Communication, language, speech, Agricultural, Folkcommunication.

Palabras clave: Comunicación, lengua, discurso, agrícola, Folkcomunicacion. 


\section{Introdução}

Tomamos o folclore como o estudo e conhecimento das tradições de um povo, porém consideramos que tradições, crenças e costumes se criam, como lembra Megale (1999:13)

toda a sociedade participa da criação e da manutenção do folclore... ele não é estático, mas essencialmente dinâmico, pois, apesar de basear-se no passado, está sempre se acomodando à mentalidade e às reivindicações do presente, ou ainda: o folclore é o retrato vivo dos sentimentos populares e das reações do povo ante as transformações sociais.

O homem vê o mundo e recorta o universo a partir de determinada perspectiva, influenciado pela sociedade, pela sua experiência, pela sua história de vida. A Rede Globo de televisão, considerando os altos índices de audiência alcançados, que permite a conservação de um programa mais de duas décadas no ar, como o caso do programa Globo Rural, que este ano comemora 25 anos de programação ininterrupta, tem o poder de dirigir audiência em determinado sentido e de criar imagens conforme padrões estereotipados.

Os episódios do Programa Globo Rural, como produtos comunicacionais mercadológicos, exibidos em mídia de massa, apóia-se na tradição do homem do campo e constrói uma imagem saudosista que se contrapõe à do homem de negócio no campo, resultante das atividades do agro-negócio. Assim, o programa coloca lado-a-lado as inovações da tecnologia no campo e a religiosidade, a culinária de fogão de lenha, a música de viola, entre outros.

Os estudos da Folkcomunicação orientados pela teoria de Luiz Beltrão, segundo o qual a "folkcomunicação é o processo de intercâmbio de informações e manifestações de opiniões, idéias e atitudes da massa, através de agentes e meios ligados direta ou indiretamente ao folclore" (BELTRÃO, 2001, p.79), neste estudo serve apenas como referência, uma vez que a Rede Globo de televisão, ainda que no contexto do Globo Rural, não se caracteriza 
como folkmídia, portanto o processo de conservar elementos folclóricos na programação faz parte de uma estratégia de prender o público ao perfil do programa e de caracterizar o homem do campo a partir destes traços folclóricos.

Porém ao se considerar o conceito desenvolvido por Hohlfeldt (2002, p.25) de que

\begin{abstract}
A folkcomunicacão não é o estudo da cultura popular ou do folclore, é bom que se destaque com clareza. A folkcomunicação é o estudo dos procedimentos comunicacionais pelos quais as manifestações da cultura popular ou do folclore se expandem, se sociabilizam, convivem com outras cadeias comunicacionais, sofrem modificações por influência da comunicação massificada e industrializada ou se modificam quando apropriadas por tais complexos,
\end{abstract}

somos levados a refletir até que ponto este Programa televisivo, no ar há 25 anos, não cumpre esta tarefa de "folkcomunicar", em uma emissora de televisão altamente massificada e plenamente contaminada pelo teor mercadológico e político.

\title{
O Programa Globo Rural
}

Em 25 anos de programação (desde 1980 no ar) foram realizadas reportagens em todos os continentes, mas sua área principal de atuação é o Brasil. No campo, o programa documenta a atividade agropecuária, mostra para toda a Rede Globo o agricultor, sua cultura, suas tradições, sua paisagem e suas aspirações.

O programa analisado, haja vista seus altos índices de audiência, tem contribuído para a divulgação da ciência no que se refere ao contexto ruralista, colaborando para a formação do cidadão do campo e sua construção de conhecimento na área, ainda que críticas possam ser tecidas sobre a seleção do que interessa para ser divulgado na televisão, em especial pela Rede Globo. 
Porém, há que se destacar a qualidade técnica da produção como forte elemento de atração e de fidelidade do público a que se destina.

Como veículo de entretenimento, sabe-se que a atenção sempre está voltada para assuntos espetaculares ou para questões muito próximas do público-alvo, no sentido de buscar a identificação, maior número de investimento publicitário e, conseqüentemente, maiores índices de audiência. "Há, no âmbito da televisão, um problema sério de repertório. Conhecemos muito pouco o que a televisão produziu efetivamente nos seus mais de cinqüenta anos de história, ou conhecemos só o pior, como se só o pior fosse televisão" (MACHADO 2000, p. 20).

Embora seu público principal seja o próprio agricultor, o Globo Rural tem boa audiência também nos centros urbanos. A relação campo/cidade tem sido muito discutida nos últimos tempos, de tal forma que o cidadão urbano, estressado com a vida tumultuada que leva, tem buscado no campo, na relação com a terra e com povo, momentos de tranqüilidade. Muitos têm optado por transferir-se para as zonas rurais, para cidades próximas à capital, outros têm procurado, na própria cidade, locais mais tranqüilos, onde, em pequenos espaços de jardins ou hortas, podem relaxar. Este cidadão encontra, também no programa Globo Rural, em especial na sua edição de domingo, este contato com o campo.

Enfim, muitas são as razões que o telespectador da cidade tem para ver o programa. Além da situação acima citada há ainda o saudosismo dos muitos exa gricultores ou filhos de agricultores e há ainda um bom número de escolas urbanas cujos professores recomendam o programa como material didático, devido ao conteúdo das reportagens e à forma como os assuntos são abordados, ilustrados e discutidos.

O site oficial da Rede globo - http://globoruraltv.globo.com - fornece informações sobre dados importantes da história do programa. Sabe-se, por exemplo, que o seu planejamento teve início na década de 70, quando as 
fronteiras agrícolas do Brasil se expandiam devido à ampliação do cultivo de grãos e as crescentes exportações, principalmente, de soja e de laranja.

Na mesma época tem-se a expansão da eletrificação rural, assim como do sinal de televisão, de tal forma que o homem do campo passou a ser uma parcela considerável de telespectadores, buscando uma programação que tratasse de assuntos diretamente ligados a sua atividade na terra.

É neste contexto que o Globo Rural foi ao ar, pela primeira vez, no dia o6 de janeiro de 1980, tendo como tema da primeira reportagem justamente a nova agricultura do cerrado. A programação original de trinta minutos de duração teve uma acolhida tão significativa que logo em seguida, a partir do domingo, 3 de agosto do mesmo ano, passou para uma hora de duração. Mais tarde, a partir de 9 de outubro de 2000, o Globo Rural passou a ser transmitido também de segunda a sexta-feira, ao vivo e em rede, às 6:30 da manhã.

\section{Linguagem e discurso}

A concepção básica que sustenta esta pesquisa é a de que o discurso não é neutro, a língua não é o espelho da realidade, mas sua representação. Todo texto apresenta uma carga de significação implícita a ser recuperada pelo leitor/ouvinte, por ocasião da atividade de produção de sentido diretamente vinculada a seu contexto e historicidade. Koch (1996, p.25), a este respeito, argumenta que

(...) toda atividade lingüística seria composta por um enunciado, produzido com dada intenção, propósito, sob certas condições necessárias para o atendimento do objetivo visado e as conseqüências da realização do objeto. ... Cabe ao ouvinte/leitor estabelecer, entre os elementos do texto e todo o contexto, relações dos mais diversos tipos, para ser capaz de compreendêlos em seu conjunto e interpretá-los de forma adequada à situação. 
Para a análise do Programa Globo Rural, o conhecimento das condições sociais, culturais e cognitivas contribui decisivamente para a compreensão do porquê de determinada mensagem, com determinado formato. Ao elaborar um texto, a partir de uma temática, o autor se coloca, selecionando palavras e argumentos, marcando sua posição diante do tema. Portanto, a análise de tais mensagens deve considerar não apenas os elementos lingüísticos concretos, mas as suas condições de produção.

(...) é preciso levar em conta, simultaneamente, a enunciação - ou seja, o evento único e jamais repetido de produção do enunciado. Isto porque as condições de produção (tempo, lugar, papéis representados pelos interlocutores, imagens recíprocas, relações sociais, objetivos visados na interlocução) são constitutivas do sentido do enunciado: a enunciação vai determinar a que título aquilo que se diz é dito (KOCH, 1984, p. 15).

Desta forma, a pesquisa utiliza fundamentos "de uma teoria do discurso capaz de conciliar a análise do texto, como sistema de regras explicativas de sua organização imanente - uma abordagem interna -, com o exame da inserção contextual do texto, considerado como pretexto do contexto - uma abordagem externa" (BARROS, 2002, p.135).

A argumentatividade é um aspecto da análise de discurso a ser considerado nesta situação, confirmando a tese de que o discurso não é imparcial ou simplesmente descritivo, sempre lhe resta um caráter argumentativo, inerente a todo e qualquer discurso. As marcas discursivas estão impregnadas de sentido:

A interação social por intermédio da língua caracteriza-se, fundamentalmente, pela argumentatividade. Como ser dotado de razão e vontade, o homem constantemente, avalia, julga, critica, isto é, forma juízos de valor. Por outro lado, por meio do discurso - ação verbal dotada de intencionalidade - tenta influir sobre o comportamento do outro ou fazer com que compartilhe determinadas de suas opiniões. É por essa razão que se pode dizer que o ato de argumentar, isto é, de orientar o discurso no sentido de determinadas conclusões, constitui o ato lingüístico fundamental, pois a todo e qualquer discurso subjaz uma ideologia, na acepção mais ampla do termo (KOCH, 1996, p.19). 
A afirmação de Santaella (1996, p.330) é pertinente para sustentar a abordagem de que toda fala traz, explícita ou implicitamente, determinados posicionamentos: "As linguagens não são inocentes nem inconseqüentes. Toda linguagem é ideológica, porque ao refletir a realidade, ela necessariamente a refrata. Há sempre, queira-se ou não, uma transfiguração, uma obliqüidade da linguagem em relação àquilo a que ela se refere”.

Já que não existe texto neutro, sempre há interesses em torno de uma questão. Segundo Pêcheux (1975) o discurso não surge no vazio. O discurso remete à formação discursiva que o originou e que é marcada por uma ideologia ali embutida. Na origem do processo discursivo há uma formação discursiva permitindo as condições de sua existência.

Segundo Maingueneau (2001, p.71) "hoje, estamos cada vez mais convictos de que o midium não é simples "meio" de transmissão do discurso, mas que ele imprime um certo aspecto a seus conteúdos e comanda os usos que dele podemos fazer”.

Desta forma, a comunicação para o entretenimento, característica da linguagem televisiva, como mais uma forma de comunicação de massa, neste contexto analisado, contribui para a construção da imagem do homem do campo e do próprio ambiente rural, à medida que a representa de forma estereotipada, reproduzindo e/ou criando conceitos que tendem a ficar arraigados socialmente.

A presente pesquisa visa abordar, com um viés analítico, o recorte ideológico da linguagem como exercício de poder pela mídia na formação do cidadão. Assim, a construção da mensagem está vinculada não apenas aos elementos lingüísticos e imagéticos concretos, mas às condições de produção e de recepção, assim como às características dos meios que a veiculam.

O pensamento é organizado pela posse e pelo uso da linguagem, vista como um processo, sempre em movimento e em constante reformulação, significando e ressignificando o universo de diferentes formas. A construção 
da mensagem seleciona recursos lexicais, sintáticos e imagéticos que revelam intenções e trazem informações implícitas, projetando posicionamentos do seu produtor e sua leitura do universo. Desvelar estas intenções subjacentes à mensagem e suas relações ideológicas manifestas constitui-se parte essencial desse processo de estudo que pretende não apenas diagnosticar, mas atuar socialmente sobre essa dada realidade, propondo, a partir de suas análises e reflexões, transformá-la.

Diante desta perspectiva, a proposta de análise do discurso sobre o rural construído pelo programa "Globo Rural" torna-se relevante à medida que contribui para o desenvolvimento do senso crítico do profissional e do pesquisador de comunicação social, tanto como produtor quanto como receptor de mensagens midiáticas.

\section{A construção da imagem do homem do campo}

Em trabalho anterior, deste mesmo Projeto de Pesquisa ${ }^{2}$ apontamos que o programa televisivo retrata o homem do campo e o tem como seu públicoalvo preferencial. Portanto, sua presença é uma constante nas reportagens. O médio e o grande produtor, já envolvido pelo Agronegócio em que se transformaram as atividades do campo, apresentam-se sempre bem trajados, quase em um estilo country, conforme a moda determina, mas o pequeno agricultor, aquele da atividade de subsistência ainda conserva o estereótipo "caipira".

Embora tenha sido preparado para a realização da reportagem, este homem do campo ainda veste roupas muito rústicas, geralmente tem uma camiseta ou um boné, destes utilizados para divulgação de produtos ou até mesmo de políticos; tem uma aparência que denota nenhum cuidado com

\footnotetext{
2 A Construção do discurso SObre O MEIO RURAL: UMA ANÁliSE do PROGRAMA "Globo Rural" - paper apresentado no Celacom/2005. Elaborado a partir de uma leitura de episódios do Programa Globo Rural, subsidiada pela Análise Crítica do Discurso.
} 
dentes, pele, cabelo ou qualquer efeito estético; a postura é de submissão em relação ao repórter e principalmente em relação à presença de uma autoridade ou especialista, ou mesmo quando está relatando seu conhecimento sobre a natureza ou sobre as plantas medicinais, por exemplo. Sua linguagem apresenta muitos erros, o que poderia caracterizá-la, conforme Barthes (1998, p.91) como um discurso acrático, aquele que está fora do poder, influenciado pelo senso comum, popular, diferenciando-se da fala dos demais envolvidos na reportagem, cujo discurso denomina-se encrático, aquele que se enuncia a partir dos múltiplos aparelhos estatais ou da comunicação de massa. Desta forma, pode-se afirmar, conforme Orlandi (1983, p.107) que para o estudo do funcionamento da linguagem as implicações sociais dos participantes devem ser levadas em conta. $\mathrm{O}$ discurso faz emergir a subjetividade da linguagem.

O programa Globo Rural, objeto desta pesquisa, cria uma imagem do homem do campo e propõe que este crie uma imagem positiva da própria emissora. Os recursos tecnológicos de que a emissora dispõe para a produção do programa resultam em vários elementos que interagem com o texto verbal, acrescentando-lhe ou simplesmente reforçando significados e construindo sentidos. A leitura da mensagem, portanto, não se restringe ao código lingüístico, mas expande-se aos demais signos imagéticos. Trata-se, portanto, de uma leitura do conjunto, considerando, sobretudo, as condições de produção e a intencionalidade na produção da mensagem.

A análise dos itens selecionados para a construção da pauta do programa, assim como a observação da composição da mensagem com todos os seus recursos, da seleção lexical, da organização da temática, juntamente com o repertório que se tem sobre o programa, sobre a emissora e sobre as questões sociais e políticas que envolvem o campo no nosso país, possibilitam a visualização da imagem do homem do campo que buscávamos na proposta inicial. 
Na visão do Globo Rural o homem do campo é aquele que precisa aprender com o cientista, com a Universidade, com o especialista; sua vivência não o credencia e não o leva ao sucesso esperado. O agronegócio, a cada dia vai tomando conta do cenário do campo e vai transformando o agricultor ou pecuarista em um homem de negócio, ficando ao pequeno agricultor o estereótipo do caipira, daquele que fala errado, que se veste mal, mas que tem uma sapiência natural, resultado da sua vivência no campo, e, por isso deve ser protegido.

O programa televisivo registra altos índices de audiência, pois, mostra imagens fascinantes de um lugar e de uma forma de se viver sem stress, deixa explícita sua preocupação em solucionar os problemas apresentados por este homem rural, em buscar as informações nas fontes mais credenciadas, enfim, de protegê-lo do "inimigo".

\section{Sobre Folclore no Globo Rural}

Temáticas vinculadas ao folclore geralmente compõem a pauta do programa, como uma forma de transportar o homem de volta para casa, inspirado em um saudosismo nem sempre justificável, ou seja, mesmo o homem urbano sente-se contagiado pela tradição e pelas histórias da terra, como se a felicidade residisse naquele espaço, ocupado geralmente pela ingenuidade.

Selecionamos algumas reportagens para exemplificar este aspecto folclórico, explorado na programação como elemento argumentativo que garante, de certa forma, a fidelidade da audiência. 
Dança na lavoura - (12/08/2004)

Um grupo de dança folclórica transformou uma plantação de cana de Olímpia, São Paulo, em palco para a cultura brasileira.

Folia de Reis - (30/12/2003)

A devoção pelos Santos Reis mantém uma manifestação folclórica de origem portuguesa que é tradição nesta época do ano.

Dança no moinho - (01/12/2003)

Grupo folclórico criado por agricultores da cooperativa Castrolanda, no sul do Paraná, completou 50 anos no fim-de-semana. O aniversário foi comemorado com muita festa e dança.

Homenagem aos pioneiros - (12/05/2003)

Os povos que ajudaram a construir o Vale do Ribeira, em São Paulo, foram homenageados em Pariqüera-Açú. A Festa das Nações teve dança folclórica e comida típica.

Bom para proteger - (19/01/2003)

Na continuação da viagem pelo folclore rural em São Paulo a reportagem traz a história de um benzedor que espanta cobras, os mistérios das noites de eclipse e a luta dos agricultores para combater um inimigo terrível.

$\mathrm{Na}$ “dança da lavoura" verifica-se a necessidade que se tem de transformar o cenário do trabalho desgastante - plantação de cana - em um palco, ou seja, em um cenário não vivenciado, mas sonhado pelo trabalhador, onde a cultura brasileira representa o seu berço. Desta forma, a televisão passa a significar um elemento capaz de resgatar a tradição e de transformar o cotidiano.

Da mesma maneira, a religiosidade, o respeito aos costumes dos imigrantes e as crenças do homem do campo têm lugar nas reportagens que exploram o folclore. Verifica-se o uso de frases curtas e chamativas nos títulos das matérias, provocando uma expectativa, à maneira publicitária de prender a audiência, deixando a explicação referencial para a introdução do texto.

Na reportagem "bom para proteger", as crenças são lembradas, inclusive recorrendo a uma autoridade no assunto:

Olho grande, quebrante, olho ruim, olho de sangue, mau-olhado. O nome varia, mas ninguém duvida de que o olho gordo é um dos inimigos mais temidos pelo povo do campo. Nas palavras do 
folclorista Câmara Cascudo, 'um olhar com fluidos perigosos e nocivos, que causam os mais variados efeitos'.

O sitiante que participa da matéria, representando o homem rural, é caracterizado como aquele que "nasceu na roça, sempre levou vida dura e nunca teve medo de trabalho. Já de olho gordo. Em busca de proteção, ele pendurou uma caveira de boi logo na entrada de seu sítio".

Para contrapor o saber tradicional do sitiante tem-se a palavra de um jornalista e historiador, Sérgio Coelho de Oliveira, que escreveu o livro Os Espantalhos, reunindo dez anos de pesquisas sobre folclore rural. Assim, vários dados sobre as pesquisas são explanados durante a matéria, na tentativa de buscar as origens das crendices.

Frente ao saber do pesquisador, o sitiante sente-se intimidado, e, em voz baixa, fala sobre sua atividade de vender cabeças de boi, como uma tradição para afastar tais maus olhados: "Eles acham que é bom para espantar mauolhado. Essas coisas antigas que o povo fala, mas que eu não acredito" revelou seu Luiz.

A mesma matéria mostra outras crendices, personagens e métodos para afastar os inimigos utilizados pelo homem do campo, caracterizados como "exército simplório, mas poderoso".

\section{Seção de Cartas e os repórteres}

O Programa recebe, em média, 1400 cartas por mês e muitas delas acabam se transformando em reportagens de até 20 minutos de duração. Conforme informações fornecidas pelo próprio programa: "entre as inúmeras sugestões que renderam matéria, destaca-se o relato do uso de um carro de boi para o transporte de milho de uma fazenda para outra, na cidade mineira de Formiga. Outro exemplo é o caso enviado por um agricultor de Sertão de Cariri, na Paraíba, que mostrou a tradição nordestina na fabricação do queijo 
coalho". Verifica-se, portanto, que a tradição recebe um destaque, é valorizada pela equipe, como uma estratégia de mostrar algo diferente, e conseqüentemente, de atrair a atenção do telespectador.

Os próprios jornalistas envolvidos no programa mostram características interioranas. A jornalista Helen Martins, responsável pela seção de cartas, além de uma das apresentadoras e, muitas vezes também repórter no campo, é paulista da cidade de São João da Boa Vista, tem suas raízes na vida caipira do interior.

José Hamilton Ribeiro, também interiorano da cidade paulista da cidade de Santa Rosa do Viterbo, desde muito moço esteve envolvido com a grande imprensa, com trabalhos nacionais e internacionais, mas sempre esteve também voltado para o interior: em São José do Rio Preto, em 1974, fundou o jornal Dia e Noite, tempos depois mudou-se para Campinas para lançar outro periódico. É o repórter mais experiente e mais respeitado no Programa. Apresenta características interioranas, na maneira de falar e vestir e relacionase com o entrevistado com respeito e atenção. A riqueza das suas reportagens rendeu-lhe vários prêmios.

Outros jornalistas, oriundos de cidades do interior, como Ivaci Matias, Ana Dalla Pria, ou mesmo Vico Iasi que é nascido na capital paulista, mostram uma identificação total com o homem do campo e com as questões que se referem a ele.

O telespectador recebe um tratamento diferenciado, pois, suas cartas pautam a organização dos episódios, apresentam problemas que exigem a busca de soluções, geralmente encontradas em pesquisas desenvolvidas pelas universidades ou Institutos de pesquisas. 


\section{A culinária no Globo Rural}

Além da religiosidade, das festas, danças e crendices, a tradição folclórica apresenta-se também na culinária, seção importante do Globo Rural. Em cenários rústicos, geralmente, composto por um fogão à lenha, gente simples e feliz ensina receitas atrativas, seja pelos ingredientes não convencionais, seja pelo processo de elaboração dos pratos.

Selecionamos algumas chamadas destas receitas para exemplificar este apego à tradição que caracteriza o homem do campo. A excentricidade é que chama a atenção e destaca-se na culinária:

\begin{tabular}{|l|l|}
\hline Nhoque de milho verde & $\begin{array}{l}\text { Aprenda a preparar o nhoque de milho verde, uma } \\
\text { receita italiana adaptada ao gosto brasileiro. }\end{array}$ \\
\hline Peixe assado com farofa & $\begin{array}{l}\text { Aprenda a fazer uma receita indígena de peixe } \\
\text { assado na brasa com farofa de água. }\end{array}$ \\
\hline Doce de marolo & $\begin{array}{l}\text { Aprenda a preparar o doce de marolo, uma fruta } \\
\text { típica do cerrado. }\end{array}$ \\
\hline $\begin{array}{l}\text { Geléia de maracujá do } \\
\text { mato }\end{array}$ & $\begin{array}{l}\text { Aprenda a preparar a deliciosa geléia de maracujá } \\
\text { do mato, receita feita com a fruta típica do } \\
\text { Nordeste. }\end{array}$ \\
\hline Cajuzinho cristalizado & $\begin{array}{l}\text { Saiba como preparar o cajuzinho cristalizado, um } \\
\text { doce tradicional no Ceará. }\end{array}$ \\
\hline Mipeva & $\begin{array}{l}\text { Aprenda a receita de mipeva, um bolinho de } \\
\text { amendoim tradicional na região do Alto Tietê, em } \\
\text { São Paulo. }\end{array}$ \\
\hline Pequizada & $\begin{array}{l}\text { Aprenda a preparar a pequizada, uma receita feita } \\
\text { com o pequi. }\end{array}$ \\
\hline Bolo de agrião & $\begin{array}{l}\text { Aprenda a preparar um bolo doce feito com a } \\
\text { verdura. }\end{array}$ \\
\hline Lingüiça com ervas & $\begin{array}{l}\text { Anote a receita da lingüiça de calabresa com ervas, } \\
\text { que faz a fama de Bragança Paulista, São Paulo }\end{array}$ \\
\hline Lingüiça de bode & $\begin{array}{l}\text { Saiba como fazer a lingüiça feita com carne de } \\
\text { bode, um embutido muito apreciado no vale do } \\
\text { São Francisco, entre Pernambuco e Bahia. }\end{array}$ \\
\hline
\end{tabular}


Há sempre um apelo explícito ao telespectador, com os imperativos: saiba, aprenda ou anote. A origem dos pratos é sempre o interior do país, as receitas da cidade não têm espaço neste contexto. Desta forma, somos levados a acreditar que também a culinária é tratada no Globo Rural como um elemento folclórico que engrandece o homem do campo. Ao ser levada para a televisão a receita ganha um status diferenciado, ganhando uma apresentação visual digna de livros de receita de grandes gourmets. As fotos que ilustram as matérias no site do programa são realmente fotos publicitárias. As receitas partem da memória do sertanejo, ou de velhos cadernos de receitas e passam a povoar, primeiramente, as telas dos aparelhos de televisão, em emissora nacional, depois ganham o ciberespaço pela internet.

\section{Considerações finais}

A influência da televisão sobre a audiência é uma questão que já foi amplamente discutida e que volta à tona, principalmente quando se trata de uma análise crítica da mídia, em especial quando esta mídia é a Rede Globo.

A presente pesquisa não se vincula a este tipo de crítica e foi realizada procurando considerar o texto, a mensagem, no seu contexto sócio-políticoideológico. Justificam-se, portanto, os pressupostos da Análise crítica do discurso, como subsídios para a leitura realizada, a partir das condições de produção. A leitura da mensagem televisiva, portanto, não se restringe ao código lingüístico, mas expande-se aos demais signos imagéticos, e a todo conjunto de informações decorrentes da participação de vários atores na produção do programa em todas as suas etapas.

O trabalho busca contribuir para uma reflexão sobre o poder da mídia de criar imagens. Neste caso, o Programa Globo Rural, no ar há 25 anos, é responsável por criar ou reforçar uma imagem do homem do campo: por um lado, a tecnologia aplicada às atividades do campo, juntamente com os 
avanços científicos, das pesquisas realizadas, deram origem um novo produtor rural, ligado ao agronegócio. Por outro lado, mantém-se a imagem do “caipira” desprotegido, caracterizado por um saber de tradição, uma imagem arraigada ao imaginário coletivo. Neste aspecto, a emissora apresenta uma visão paternalista ao buscar a solução para os seus problemas e a proteção que julga necessitar.

O conhecimento do funcionamento da linguagem, do discurso como revelador da subjetividade, propicia uma leitura mais crítica e desvela elementos implicitados na organização da mensagem. Desta forma é possível entender, além do conteúdo semântico da mensagem, a imagem que é elaborada dos atores envolvidos no processo comunicativo. O programa globo Rural, objeto desta pesquisa, cria uma imagem do homem do campo e propõe que este crie uma imagem positiva da própria emissora.

Aspectos folclóricos são pautados pelo programa, muitas vezes oriundos de cartas dos próprios telespectadores, como recursos argumentativos para dirigir o olhar e fortalecer a imagem que se quer construir. Pudemos observar que, primeiramente a própria ambientação do programa (com músicas e cenários), caracterização e origens dos repórteres, depois as danças, festas religiosas, assim como a culinária, são responsáveis por compor as tradições do homem da terra.

O programa Globo Rural, desta forma, revitaliza o folclore, inserindo-o na mídia de massa, da mesma forma que passa ele próprio, a ser considerado como um elemento folclórico, se assim podemos chamar, um programa que passou a fazer parte do cotidiano daquele público. A música de abertura do Globo Rural tem o mesmo efeito das músicas sertanejas ou caipiras, que há décadas, no rádio, nos programas matutinos, às cinco horas da manhã, se mesclam ao cheiro de café recém-coado, ao fogão à lenha e à vida simples. 


\section{REFERÊNCIAS BIBLIOGRÁFICAS}

BARROS, Diana Luz Pessoa de. Teoria do discurso: fundamentos

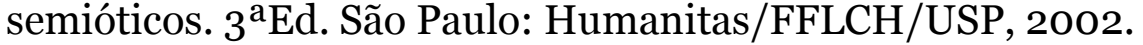

BARTHES, Roland. O rumor da língua. São Paulo: Brasiliense, 1998.

BELTRÃO, Luiz. Folkcomunicação: um estudo dos agentes e dos meios populares de informação de fatos e expressão de idéias. Porto Alegre: EDIPUCRS, 2001.

HOHLFELDT, Antonio. Folkcomunicação: positivo oportunismo de quase meio século. in: Anuário UNESCO/UMESP de comunicação regional, v. 1, n. 5, São Bernardo do Campo - SP, 2002.

KOCH, I. V. O texto e a construção dos sentidos. São Paulo: Cortez, 1984.

KOCH, Ingdore Vilhaça. A Inter-ação Pela Linguagem. São Paulo. Contexto, 1996

MACHADO, Arlindo. A Televisão Levada a Sério. São Paulo, SENAC, 2000.

MAINGUENEAU, Dominique. Análise de textos de comunicação. São Paulo: Cortez, 2001.

MEGALE, Nilza Botelho. Folclore Brasileiro. Petrópolis, RJ : Vozes, 1999.

ORLANDI, Eni Pulcinelli. A Linguagem e seu Funcionamento. As formas do discurso. São Paulo: Brasiliense, 1983.

PÊCHEUX, Michel. Análise do Discurso. Paris: Larousse, 1975.

SANTAELLA, Lúcia. A produção de linguagem e ideologia. São Paulo: Cortez, 1996. 